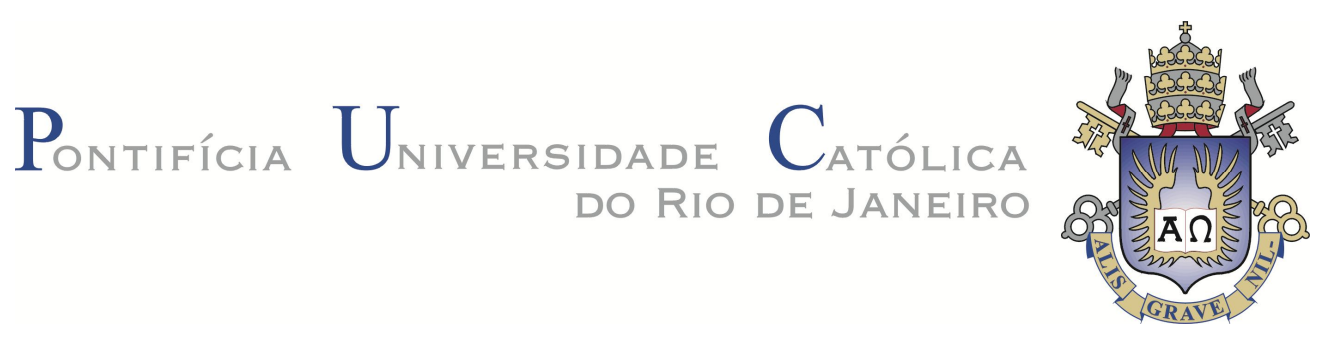

David Marinho de Lima Júnior

\title{
Descolonizando as mentes: Ousmane Sembène e a proposta de um Cinema Africano na década de 1960
}

Dissertação de Mestrado

Dissertação apresentada como requisito parcial para obtenção do grau de Mestre pelo Programa de Pós-Graduação em História Social da Cultura do Departamento de História do Centro de Ciências Sociais da PUC-Rio.

Orientador: Prof. Maurício Barreto Alvarez Parada 


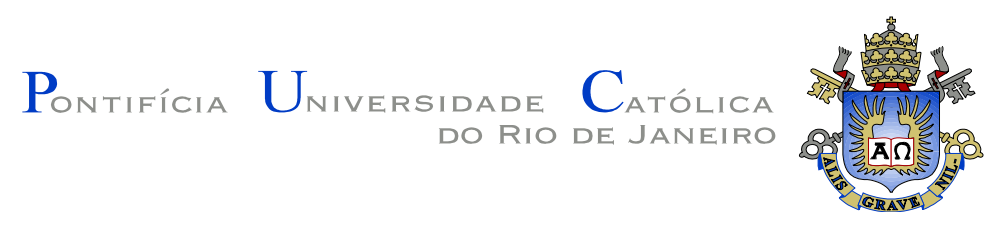

David Marinho de Lima Junior

\title{
Descolonizando as mentes: \\ Ousmane Sembène e a proposta de um Cinema Africano \\ na década de 1960
}

\begin{abstract}
Dissertação apresentada como requisito parcial para obtenção do grau de Mestre pelo Programa de Pós-Graduação em História Social da Cultura do Departamento de História do Centro de Ciências Sociais da PUC-Rio.

Aprovada pela Comissão Examinadora abaixo assinada.
\end{abstract}

\author{
Profo Maurício Barreto Alvarez Parada \\ Orientador \\ Departamento de História - PUC-Rio
}

Prof ${ }^{\text {a }}$ Regiane Augusto de Mattos

Departamento de História - PUC-Rio

Profo Marcelo Bittencourt Ivair Pinto Centro de Estudos Gerais Instituto de Ciências Humanas e Filosofia

Departamento de História - UFF

Profa Mônica Herz Vice-Decana de Pós-Graduação do Centro de Ciências Sociais PUC-Rio

Rio de Janeiro, 10 de outubro de 2014. 
Todos os direitos reservados. É proibida a reprodução total ou parcial do trabalho sem a autorização da universidade, do autor e do orientador.

\section{David Marinho de Lima Junior}

Graduou-se em História pela Universidade Federal do Rio de Janeiro em 2010. Possui especialização em História da África e do Negro no Brasil pelo IUPERJ/UCAM. É professor do ensino fundamental e médio na Prefeitura Municipal de Cabo Frio desde 2011.

Ficha Catalográfica

Lima Júnior, David Marinho de

Descolonizando as mentes: Ousmane Sembène e a proposta de um cinema africano na década de 1960 / David Marinho de Lima Júnior ; orientador: Maurício Barreto Alvarez Parada. 2014.

115 f. : il. (color.) ; $30 \mathrm{~cm}$

Dissertação (mestrado)-Pontifícia

Universidade Católica do Rio de Janeiro, Departamento de História, 2014.

Inclui bibliografia

1. História - Teses. 2. Sembène, Ousmane. 3. Cinema. 4. História da África. 5. Descolonização. 6. Senegal. I. Parada, Maurício Barreto Alvarez. II. Pontifícia Universidade Católica do Rio de Janeiro. Departamento de História. III. Título.

CDD: 900 
Para todos aqueles que lutam por um mundo mais justo Pela inspiração cotidiana 


\section{Agradecimentos}

Terminar essa etapa da minha vida acadêmica requer realmente muitos agradecimentos, não foi fácil seguir esse caminho e nada disso seria possível sem o apoio, o incentivo e os puxões de orelha de pessoas muito queridas.

Em especial gostaria de agradecer à Larissa por ter acompanhado tudo desde o início, pelo companheirismo, pelas risadas, pelo "acaba logo com isso", mas acima de tudo pela doce e linda aventura.

Agradeço muito aos meus pais por estarem sempre do meu lado e apoiarem minhas escolhas, assim como toda minha família. Gostaria de agradecer especialmente minha prima Geórgia, Jerry, Giuliano e o mais novo integrante da família, Enrico, por me receberem sempre tão bem na casa de vocês. Aos meus irmãos, Iana e João Pedro, pelo amor e carinho de sempre.

Agradeço profundamente os amigos e amigas de longa data e tantas histórias: Alexandre, Felipe, Diego, Luiz, Eduardo, Guto, Rafaela, Marcelo, Rafael Andrade, Rafael Aires, Rafael Pinto, Rafael Alexandre, Rafael Candido, João Felipe, Caio e Spinelli.

Aos amigos mais recentes e igualmente queridos: Mariano, Hannah, Pedro, Isabela, Julia e Luana. Ao que o IFCS me proporcionou de melhor: Aline, Cecília, Claudinha, Ademir, Arnaldo, Gerson, Carla, Leonardo, Bia, Silvia, Alisson, Sandro, Camila, Natália, Kelly e Fernanda.

Agradeço muito ao meu orientador Maurício Barreto Alvarez Parada pelo incentivo, apoio e disponibilidade. A professora Regiane Augusto de Mattos, por ser uma das maiores incentivadoras do meu trabalho, muito obrigado pelos convites e oportunidades. Ao professor Marcelo Bittencourt pelas inúmeras contribuições, pela disponibilidade e generosidade. Ao professor Murilo Sebe, a quem serei sempre grato por acreditar no meu trabalho desde a graduação e pelo companheirismo que sempre demonstrou.

À CAPES e à PUC-Rio pelos auxílios concedidos sem os quais este trabalho não poderia ter sido realizado e aos demais colegas da turma de mestrado, em especial Desirree e William, com quem compartilhei as angústias dessa reta final.

À todos, mais uma vez, meu muito obrigado 


\section{Resumo}

Lima Júnior, David Marinho de; Parada, Mauricio Barreto Alvarez. Descolonizando as mentes: Ousmane Sembène e a proposta de um Cinema Africano na década de 1960. Rio de Janeiro, 2014. 115p. Dissertação de Mestrado - Departamento de História, Pontifícia Universidade Católica do Rio de Janeiro

O colonialismo europeu teve um grande impacto nas sociedades africanas e é sentido até os dias de hoje. Mesmo com as lutas de independência no pós Segunda Guerra Mundial, o peso do domínio colonial se faz presente, especialmente no campo da cultura. A "descolonização das mentes" foi um desafio assumido pelos intelectuais engajados nas lutas de independência, principalmente aqueles de origem africana. $\mathrm{O}$ cinema se tornou uma importante ferramenta nesse processo, surgindo pela primeira vez a proposta de um Cinema Africano, no âmbito da antiga África Ocidental Francesa durante a década de 1960. Este trabalho analisa a produção cinematográfica do senegalês Ousmane Sembène durante o período supracitado. Sua proposta de cinema e sua militância influenciaram muitos artistas e intelectuais africanos, sua busca por uma estética que rejeitasse os padrões europeus e de Hollywood é considerada por muitos a fundação do que se costuma chamar de Cinema Africano. Esta dissertação tem como objetivo contribuir para a análise dos elementos que compõe essa proposta estética e o debate sobre a possibilidade de um Cinema Africano. Além disto, o trabalho se propõe ainda a se debruçar sobre a trajetória de vida de Sembène, seu processo de formação intelectual e seu exílio numa tentativa de estabelecer a conexão entre o artista formado e suas origens, através de sua biografia e suas entrevistas, investigando dessa maneira as relações sociais que deram origem ao cineasta.

\section{Palavras-chave}

Ousmane Sembène; Cinema; História da África; Descolonização; Senegal 


\section{Abstract}

Lima Júnior, David Marinho de; Parada, Mauricio Barreto Alvarez (Advisor) Decolonizing the minds: Ousmane Sembène and the proposal of an African Cinema in the 1960s. Rio de Janeiro, 2014. 115p. MSc. Dissertation - Departamento de História, Pontifícia Universidade Católica do Rio de Janeiro

European colonialism had a great impact on African societies and is felt to this day. Even with the struggles for independence in the post World War II, the weight of colonial rule is present, especially in the field of culture. The "decolonization of the minds" was a challenge taken up by intellectuals engaged in the process of decolonization, especially those of African origin. The cinema has become an important tool in this process, appearing for the first time a proposed African Cinema, under the former French West Africa during the 1960s. This paper analyzes the cinematic of the senegalese Ousmane Sembène during the stated period. His proposal for an african cinema and his activism influenced many African artists and intellectuals, his quest for an aesthetic that rejected the European and Hollywood standards is considered by many the foundation of what is called African Cinema. This dissertation aims to contribute to the analysis of aesthetic elements that make up this proposal and the debate about the possibility of an African Cinema. In addition, the study aims to further look into the life trajectory of Sembène, the process of intellectual formation and his exile in an attempt to establish the connection between the artist and his origins, through his biography and his interviews, investigating this way the social relations that gave rise to the filmmaker.

\section{Keywords}

Ousmane Sembène; Cinema; African History; Decolonization; Senegal 


\section{Sumário}

1. Introdução

2. Ousmane Sembène: as origens de um artista militante

2.1 Da Casamansa ao porto de Marselha

2.2 Colonialismo e a África Ocidental Francesa

2.3 Sembène e a perspectiva africana de um artista militante

3. O cinema africano

3.1. O que é o Cinema africano?

3.2. O pioneirismo do cinema na África negra francófona

4. Uma análise isotópica da obra de Ousmane Sembène

5. Conclusão 


\section{Abreviaturas e siglas}

ADEAC (Association pour le Développement des Échanges Artistiques et Culturels)

AEF

AO

CAI

CGT

(África Equatorial Francesa)

(África Ocidental Francesa)

(Consortium Audiovisuel International)

(Confédération générale du travail)

CIDIC (Consortium Inter-Africain de Distribution Cinématographique)

Ciprofilm

CNC

Comacico

Fepaci

Fespaco

IDHEC

JCC

MFDC

OAU

OCAM

SECMA

Sopacia
(Consortium Inter-Africain de Production du Film)

(Centre National de la Cinématographie)

(Compagnie Africain Cinématographique et Comerciale)

(Fédération Panafricaine des Cinéastes)

(Festival Panafricain de Ouadagoudou)

(Institute des Hautes Études Cinématographiques)

(Journées Cinématographiques de Carthage)

(Mouvement des forces démocratiques de Casamance)

(Organization of African Unity)

(Organisation Commune Africaine et Mauritienne)

(Société d'Explotation Cinématographique Africaine)

(Société de Participation Cinématographique Africaine) 
